\title{
Origem do Centro de Educação Rural Clementino Coelho: entre história e memória (Petrolina, PE, 1977-1984)
}

\author{
Origin of the Clementino Coelho Rural Education Center: between \\ history and memory (Petrolina-PE, 1977-1984)
}

\section{Origen del Centro de Educación Rural Clementino Coelho: entre historia y memoria (Petrolina-PE, 1977-1984)}

\begin{abstract}
Manuela Garcia de Oliveira'
Universidade de Pernambuco, Pesquisadora do Grupo de Estudos e Pesquisas em História da
\end{abstract} Educação no Sertão do São Francisco

\section{Uirgínia Pereira da Silua de Avila²}

Universidade de Pernambuco, Professora adjunta do Colegiado de Pedagogia e do Programa de Pós-graduação em Formação de Professores e Práticas Interdisciplinares

Resumo: Este texto analisa a origem do Centro de Educação Rural Clementino Coelho, no Município de Petrolina, Estado de Pernambuco, no período entre 1977 e 1984, no contexto do Sistema Integrado de Educação Rural concebido pelo Instituto Interamerciano de Cooperação Agrícola. A delimitação temporal compreende a data de início do funcionamento da escola e da alteração curricular que retirou o ensino das técnicas agrícolas nas turmas de $1^{\circ}$ grau. Quanto aos aspectos teóricometodológicos, a pesquisa é de cunho histórico e documental. Entre as fontes selecionadas para o estudo, destaca-se um conjunto de documentos, entre os quais: planta arquitetônica, cadernos de professores, livro de cadastro das unidades escolares de Pernambuco, periódicos da Secretaria da Educação e relatórios do Instituto Interamericano de Cooperação Agrícola (IICA). Além das fontes mencionadas, a pesquisa se valeu da metodologia da História Oral, por meio de entrevistas gravadas, uma vez que a história oral recupera e dá vida ao que não está exposto no documento escrito. Foram selecionados uma ex-professora e três ex-estudantes, utilizando como critérios o tempo de atuação na instituição, bem como o período de estudo, no caso dos ex-estudantes. A análise dos documentos, entrecruzada com as fontes orais, permitiu observar a abrangência do Sistema Integrado de Educação Rural (SIER) no estado pernambucano e evidenciou a baixa adesão do CERU Clementino Coelho aos eixos norteadores do programa. Por fim, o estudo aponta para a necessidade

Mestre em Educação pela Universidade de Pernambuco; Graduada em Letras, Língua Portuguesa, pela Universidade de Pernambuco; http://orcid.org/0000-0002-8462-6216; http://lattes.cnpq.br/5037045494505166.

2 Doutora em Educação Escolar pela Universidade Estadual Paulista Júlio de Mesquita Filho; Mestre em Educação pela Universidade do Estado de Santa Catarina; http://orcid.org/0000-0002-2634-1474; http://lattes.cnpq.br/4618776221936510. 
de investigações mais aprofundadas sobre o papel desempenhado pelo SIER na criação dos Centros de Educação Rural no Estado de Pernambuco.

Palavras-chave: Centro de Educação Rural Clementino Coelho. Sistema Integrado de Educação Rural. História da Educação. Pernambuco.

Abstract: This text examines the origin of the Clementino Coelho Rural Education Center in the Municipality of Petrolina, State of Pernambuco, between 1977 and 1984, in the context of the integrated rural education system conceived by the Interamerciano Institute of Cooperation Agricultural. The temporal delimitation comprises the starting date of the school and the curricular alteration that withdrew the teaching of agricultural techniques in the 1st degree classes. As for the theoretical and methodological aspects, the research is of historical and documental nature. Among the sources selected for the study, we highlight a set of documents, including: architectural plan, teacher notebooks, registration book of the school units of Pernambuco, periodicals of the Secretariat of Education and reports of Inter-American Institute for Agricultural Cooperation (IICA). In addition to the sources mentioned, the research was based on the methodology of oral history, through recorded interviews, since oral history recovers and gives life to what is not exposed in the written document. A former teacher and three former students were selected, using as criteria the time of work in the institution, as well as the study period, in the case of the former students. The analysis of the documents, intertwined with the oral sources allowed observing the coverage of the SIER in the State of Pernambuco, as evidenced by the low adherence of Ceru Clementino Coelho to the guiding axes of the program. Finally, the study points to the need for deeper investigations on the role played by the integrated rural education system in the creation of rural education centers in the State of Pernambuco.

Keywords: Clementino Coelho Rural Education Center. Integrated Rural Education System. History of Education. Pernambuco.

Resumen: Este texto examina el origen del Centro de Educación Rural Clementino Coelho en el Municipio de Petrolina, Estado de Pernambuco, entre 1977 y 1984, en el contexto del sistema integrado de educación rural concebido por el Instituto Interamerciano de Cooperación Agrícola. La delimitación temporal comprende la fecha de inicio de la escuela y la alteración curricular que retiró la enseñanza de las técnicas agrícolas en las clases de ler grado. En cuanto a los aspectos teóricos y metodológicos, la investigación es de carácter histórico y documental. Entre las fuentes seleccionadas para el estudio, destacamos un conjunto de documentos, entre ellos: plan arquitectónico, cuadernos de profesores, libro de registro de las unidades escolares de Pernambuco, publicaciones periódicas de la Secretaría de educación y informes de Instituto Interamericano de cooperación Agropecuaria (IICA). Además de las fuentes mencionadas, la investigación se basó en la metodología de la historia oral, a través de entrevistas grabadas, ya que la historia oral recupera y da vida a lo que no está expuesto en el documento escrito. Se seleccionó a un ex docente y a tres ex-alumnos, utilizando como criterio el tiempo de trabajo en la institución, así como el período de estudio, en el caso de los antiguos alumnos. El análisis de los documentos, entrelazados con las fuentes orales permitieron observar la cobertura de 
la SIER en el Estado de Pernambuco, como lo demuestra la baja adherencia de Ceru Clementino Cooelho a los ejes rectores del programa. Por último, el estudio señala la necesidad de realizar investigaciones más profundas sobre el papel desempeñado por el sistema educativo rural integrado en la creación de centros de educación rural en el Estado de Pernambuco.

Palabras clave: Centro de Educación Rural Clementino Coelho. Sistema Educativo Rural Integrado. Historia de la Educación. Pernambuco.

Recebido em 11 de agosto de 2018

Aceito em 16 de outubro de 2018

Publicado em 19 de fevereiro de 2019

\section{NOTAS INTRODUTÓRIAS}

Neste texto analisamos a origem do Centro de Educação Rural Clementino Coelho, no Município de Petrolina, Estado de Pernambuco, no período entre 1977 e 1984 , no contexto do Sistema Integrado de Educação Rural (SIER) concebido pelo Instituto Interamerciano de Cooperação Agrícola (IICA). A delimitação temporal compreende a data de início do funcionamento da escola e da alteração curricular que retirou o ensino das técnicas agrícolas nas turmas de $1^{\circ}$ Grau, componente curricular ${ }^{3}$ que norteava uma das caracaterísticas rurais da Instituição.

As décadas de 1960 e 1970, no Brasil, inauguraram uma nova dinâmica em diversos setores, como político, social, econômico e educacional em detrimento da Ditadura CivilMilitar implantada nesse período, que tinha como subterfúgios a instauração da normalidade econômica, a preservação do capitalismo e a segurança nacional contra a dominação do pensamento comunista, principalmente pelos grupos mais conservadores. Diante desse novo cenário, o País, que detinha vocação agrícola e estava em processo de industrialização, ainda encarava a escassez de políticas específicas ${ }^{4}$ com resultados tangíveis, principalmente no plano educacional, destinadas à comunidade rural.

\footnotetext{
3 No artigo é utilizado o termo componente curricular, de acordo com o Ministério da Educação (MEC), porém no período estudado o termo utilizado ainda era disciplina.

4 É pertinente salientar que as décadas precedentes, 1940 e 1950, foram marcadas por campanhas de iniciativas federais desenvolvidas pelo Ministério da Educação (MEC), como a Campanha de Educação de Adultos e Adolescentes (CEAA), a Campanha Nacional de Educação Rural (CNER), a Campanha Nacional de Erradicação do Analfabetismo (CNEA) e o Movimento de Educação de Base (MEB), este em parceria com a igreja católica.
} 
Novos programas e projetos da década de 1970 surgem norteados pela ideia de Desenvolvimento Rural Integrado (DRI) com cooperação entre os organismos internacionais e o Ministério da Educação. Inseridos nesse novo ideário de pensar as zonas rurais do País, os CERUs são criados pelo Sistema Integrado de Educação Rural, projeto que teve atuação em dois estados, Pernambuco e Ceará.

Quanto aos aspectos teórico-metodológicos, a pesquisa é de cunho histórico e documental. Entre as fontes selecionadas para o estudo, destaca-se um conjunto de documentos, entre os quais: planta arquitetônica, cadernos de professores, livro de cadastro das unidades escolares de Pernambuco, periódicos da Secretaria da Educação e relatórios do Instituto Interamericano de Cooperação Agrícola (IICA). Para tanto, confrontamse as normas prescritas nos documentos e adota-se o que sugere Le Goff (2003 apud AVILA, 2013b), que é desmontar, desestruturar essa construção e analisar suas condições de produção com base no contexto político, social, educacional e econômico do período em tela.

Além das fontes mencionadas, a pesquisa se valeu da metodologia da História Oral, por meio de entrevistas gravadas, uma vez que a história oral recupera e dá vida ao que não está exposto no documento escrito, como aponta Alberti (2005). Foram selecionados uma ex-professora e três ex-estudantes, utilizando como critérios o tempo de exercício no magistério na Instituição, bem como o período de estudo, no caso dos ex-estudantes. Com isso, adotamos a perspectiva da História Oral temática, aqui compreendida como o acesso à memória, isto é, ao registro de uma ação individual ou coletiva, à lembrança de um tempo que não pode ser omitido - que viabiliza não somente o reencontro com o passado, mas, sobretudo, na reconstrução e reflexão do vivido. Como assinala Le Goff (2013), a memória tem a "[...] propriedade de conservar certas informações, remete-nos em primeiro lugar a um conjunto de funções psíquicas, graças às quais o homem pode atualizar impressões ou informações passadas, ou que ele representa como passadas." (LE GOFF, 2013, p. 387).

Essa "atualização" recorre a aspectos que materializam as lembranças, como os sentidos (biológicos e psicológicos), os locais e o tempo. No que se refere a isso, Nora (1993) chama de "lugares de memória", na qual explica que o homem tem a necessidade de estabelecer lugares e objetos como repositórios de memória.

No tocante ao aporte teórico-metodológico, a pesquisa se valeu dos referenciais da Nova História Cultural (NHC), sobretudo dos estudos relacionados à cultura escolar e à memória. A NHC é aqui compreendida na perspectiva de Pesavento (2003, p. 22), isto é, como uma proposta que busca "[...] decifrar a realidade do passado por meio das suas representações, tentando chegar àquelas formas, discursivas e imagéticas, pelas quais os homens expressaram a si próprios e o mundo." 
Como forma de organização, o texto divide-se em quatro seções. A primeira seção trata do contexto de criação e características do CERU Clementino Coelho; a segunda, dos programas governamentais que viabilizaram a sua construção, recursos materiais e financeiros, bem como semelhanças e diferenças em relação aos Ginásios Orientados para o Trabalho; a terceira dedica-se à estrutura arquitetônica e ao uso do espaço escolar; a quarta trata da organização curricular do ensino ministrado no CERU Clementino Coelho. Por fim, são tecidas algumas considerações e principais resultados.

\section{A CRIAÇÃO DO CENTRO DE EDUCAÇÃO RURAL CLEMENTINO COELHO}

Iniciando suas atividades em 1977, por meio do Decreto n. 4.812, de 23 de novembro de 1977, na Cidade de Petrolina, no sertão pernambucano, o Centro de Educação Rural (CERU) Clementino Coelho ${ }^{5}$ foi considerado o primeiro do Estado com capacidade para atender 1.200 alunos. Sua implantação foi oriunda da articulação entre programas e projetos do Governo Federal e Estadual, além de incentivos de instituições internacionais.

Dada a importância do acontecimento para a região, a instalação do Centro foi noticiada no Jornal do Commercio n. 246 (PERNAMBUCO, 1976b) e no Diário Oficial de Pernambuco n. 198, ano 53 (PERNAMBUCO, 1976a). A solenidade de inauguração foi presidida no dia 21 de outubro de 1976 pelo Secretário da Educação e Cultura do Estado de Pernambuco, à época José Jorge Lima, representando o Governador Francisco Moura Cavalcanti (eleito pela Assembleia Legislativa em 1974).

0 CERU Clementino Coelho emergiu no contexto político da Ditadura Civil-Militar, no governo do Presidente Ernesto Geisel (1974-1979) e da Reforma de Ensino de $1^{\circ}$ e $2^{\circ}$ Graus (Lei n. 5.692/71), que tornou o ensino profissional obrigatório. Como bem destacado por Frattini (2011), nessa reforma foram agrupados os antigos ensinos primário e ginasial em uma escola única de $1^{\circ}$ Grau, com oito anos de duração. Além disso, a formação acadêmica, que era extensiva a todo o território nacional, foi substituída por uma formação técnicaprofissionalizante.

Fruto do projeto do Sistema Integrado de Educação Rural (SIER), o CERU Clementino Coelho compôs uma das unidades operativas desse sistema de ensino cujas diretrizes estavam pautadas em um conjunto programado e integrado de ações educativas

\footnotetext{
0 nome da escola foi criado para homenagear o Sr. Clementino Coelho, popularmente conhecido como Coronel Quelê, um dos
} representantes da família que detinha o poder no âmbito político local, estadual e federal no período em questão. 
diversificadas e flexíveis. 0 sistema se organizava em torno da elaboração de propostas educacionais voltadas às comunidades rurais ${ }^{6}$ e seguia uma concepção de Desenvolvimento Rural Integrado, uma nova expressão e diferente enfoque para o progresso da agricultura, surgido na década de 1960, sob a égide da integração da agricultura, da indústria e do serviço na zona rural, mediante ação harmônica entre diversos setores governamentais (TÁVORA FILHO; LEITE, 1978).

0 SIER foi concebido pelo Instituto Interamericano de Cooperação Agrícola - IICA na década de 1970, em parceria com o Governo federal, por intermédio do Ministério da Educação. 0 economista e administrador pernambucano José Irineu Cabral ${ }^{9}$ esteve à frente da direção do IICA-Brasil entre os anos 1963 e 1964, retomando em 1971 e atuando durante três anos, após coordenar o Comitê Interamericano para o Desenvolvimento Agrícola (CIDA). Na área de educação, sobretudo na coordenação do SIER, no período de 1977 a 1986, esteve sob a direção do argentino Jorge Ricardo Werthein ${ }^{10}$ (INSTITUTO INTERAMERICANO DE COOPERAÇÃO PARA AGRICULTURA, 1990).

No Estado de Pernambuco, o IICA prestava assistência à Secretaria de Educação na programação e execução do Sistema Integrado de Educação Rural. Sua atividade principal consistia em assessorar a equipe de Educação Rural da Diretoria de Serviços Educacionais no planejamento e implantação do programa de educação rural e no desenvolvimento de um currículo rural participativo (BRASIL, 1983).

Entre as atividades gerais, o relatório destaca a definição e a implantação de uma proposta de desenvolvimento curricular participativo para o Agreste Setentrional do Estado de Pernambuco. Essa região foi escolhida como área de laboratório das primeiras experiências do Sistema e da implantação de um Plano de Desenvolvimento Rural Integrado (PDRI), promovido pelo Polonordeste." Esse trabalho foi iniciado no

6 Calazans et al. (1981), em seu estudo retrospectivo da educação rural no Brasil, destaca que o surgimento de programas direcionados para a educação rural coincide com o início do processo de industrialização, na década de 1930, processo esse que intensificou o êxodo rural e a urbanização mal projetada.

70 IICA é um organismo internacional fundado em 1942, especializado em agricultura e bem-estar rural vinculado à Organização dos Estados Americanos (OEA). Seu principal objetivo é a realização de uma agricultura competitiva, sustentável e inclusiva para as Américas. No Brasil, o IICA atua desde 1964 (REPRESENTAÇÃO..., 2018).

8 As décadas que antecederam 1970, especificadamente 1940 a 1960, foram marcadas por uma multiplicidade de programas e campanhas educacionais para as zonas rurais que, num aspecto global, foram insuficientes para equacionar a magnitude da problemática da educação rural (PERNAMBUCO, 1982).

9 José Irineu Cabral é economista e administrador. Em sua trajetória profissional, dedicou-se ao gerenciamento de instituições rurais, como a criação da Empresa Brasileira de Pesquisa Agropecuária (Embrapa), do Instituto Interamericano de Cooperação para a Agricultura (IICA), do Comitê Interamericano de Desenvolvimento Agrícola (Cida) e do Departamento de Projetos Agrícolas do Banco Interamericano de Desenvolvimento (BID).

10 Jorge Ricardo Werthein é doutor em Educação pela Universidade de Stanford (1974). Atualmente é vice-presidente da SANGARI do BRASIL. Foi representante e diretor da Organização das Nações Unidas para a Educação, a Ciência e a Saúde (Unesco) no Brasil, durante o período de 1994 a 2005.

" Programa de Desenvolvimento de Áreas Integradas do Nordeste, criado pelo Decreto n. 74.794, de 30 de outubro de 1974, cuja finalidade era promover o desenvolvimento e a modernização das Atividades Agropecuárias de áreas prioritárias do 
Governo de Marco Antônio Maciel (1979-1982), pelas mãos do Secretário da Educação, Joel de Hollanda Cordeiro.

Sinteticamente, três aspectos conceituais guiaram as estratégias educativas do sistema. 0 primeiro diz respeito a uma educação como um processo mais amplo que a escola; o segundo, uma imbricada relação entre a escola e o mundo do trabalho; e a integração de escola-educação na comunidade (WERTEIN,1981).

0 IICA mantinha unidades operativas do SIER nos Estados de Pernambuco e Ceará, bem como em outras regiões do Brasil, como Espírito Santo, Amazônia e Rio de Janeiro, com o Programa de Educação Rural Comunitária, de acordo com o Relatório do IICA no Brasil (1982) (BRASIL, 1983).

0 sistema se estruturava em três níveis operativos inter-relacionados, conforme se observa no Quadro 1.

Quadro 1 - 0s três níveis operativos do SIER

\begin{tabular}{|c|c|c|}
\hline Escolas de Base (EB) & $\begin{array}{l}\text { Escolas Inter- } \\
\text { mediárias (El) }\end{array}$ & Centros de Educação Rural (CERU) \\
\hline $\begin{array}{l}\text { Pequena escola } \\
\text { rural }\end{array}$ & Elo entre EB e CERU & Apoio técnico às EB e El \\
\hline $\begin{array}{l}\text { Ensino de } 1^{a} \text { a } 4^{a} \\
\text { série. } \\
\text { Ensino supletivo. }\end{array}$ & $\begin{array}{l}\text { Ensino de } 1^{a} \text { a } 4^{a} \\
\text { série, na educação } \\
\text { de adultos. } \\
\text { Promoção de orga- } \\
\text { nização comunitária. }\end{array}$ & $\begin{array}{l}\text { Ensino de } 1^{\circ} \text { e } 2^{\circ} \text { Graus (profissionalizante para o meio rural). } \\
\text { Ensino Supletivo. } \\
\text { Organização comunitária e cooperativismo. } \\
\text { Formação de professores leigos e aperfeiçoamento do pessoal } \\
\text { docente e administrativo. }\end{array}$ \\
\hline
\end{tabular}

Fonte: os autores.

A escolha da estratégia educacional da região a ser atendida pelo SIER levava em consideração fatores como o contexto socioeconômico da população rural, sobretudo no tocante à produção e ao mercado de trabalho; a vunerabilidade dos setores mais pobres da população, caracterizados por rendas inferiores a um salário mínimo, além do reduzido acesso à terra, cujo tamanho médio se constituía em limitação para uma população pouco rentável. (PERNAMBUCO, 1982). Nesses aspectos, as características geográficas e

\footnotetext{
Nordeste. 0 Art. $2^{\circ}$ previa as áreas integradas, preliminarmente selecionadas, I - Áreas dos Vales Úmidos, compreendendo porções do vale do Rio Parnaíba lo Delta do Parnaiba, nos Estado do Maranhão e Piauí, os vales do Gurguéia e do Fidalgo, no Estado do Piaui), vales do Nordeste Oriental (Vales do Jaguaribe, no Estado do Ceará e Apodi, Piranhas-Açu e Ceará Mirim, no Estado do Rio Grande do Norte) e porções do vale do Rio São Francisco (Vale do Moxotó, no Estado de Pernambuco, Áreas de Petrolina-Juazeiro, nos Estados de Pernambuco e Bahia, Vales dos Rio Grandes e Corrente, no Estado da Bahia, e Área do Jaiba, no Estado de Minas Gerais); entre outras áreas (BRASIL, 1974).
} 
socioeconômicas do Município de Petrolina e adjacências ${ }^{12}$ os constituíram como um local propício para a instalação do projeto.

Com 61.252 habitantes na década de 1970, o Município de Petrolina vivenciava um crescimento demográfico acentuado, e na década de 1980, atingiu uma marca de 104.096 habitantes, passando, assim, por um "crescente progresso", como menciona Padilha (1982), historiador local. Foi um momento em que a cidade recebeu diversos migrantes de regiões circunvizinhas, sendo um dos fatores atrativos a construção da Usina Hidrelétrica de Sobradinho, BA, e o desenvolvimento do setor industrial e da agricultura irrigada. Esse aspecto acerca do crescimento populacional merece destaque, pois, como ressalta Viñao Frago (2001, p. 75), é preciso "analisar a projeção espacial do estabelecimento de ensino e as relações com seu entorno." Esse entorno envolve o contexto que influenciou a instalação da escola.

A Tabela apresentada a seguir foi elaborada com base nos dados do livro Cadastro das Unidades Escolares de Pernambuco de 1977, edição do periódico Educação, confeccionado pelo Governo do Estado. 0 Governador do Estado de Pernambuco à época era o Dr. José Francisco de Moura Cavalcanti (1975-1979) e o Vice-governador era o Dr. Gustavo Paulo de Araújo Cunha. A Secretaria de Educação e Cultura estava sob a direção do Dr. José Jorge de Vasconcelos Lima.

Nesse livro estão listadas todas as escolas municipais, particulares e estaduais situadas no Estado de Pernambuco no ano 1977.

Tabela 1 - Número de escolas na Cidade de Petrolina em 1977

\begin{tabular}{cccccc}
\hline & Escolas zona urbana & & \multicolumn{2}{c}{ Escolas zona rural } \\
\hline Municipal & Estadual & Particular & Municipal & Estadual & Total \\
6 & 16 & 12 & 51 & 8 & 93 \\
\hline
\end{tabular}

Fonte: os autores.

É possivel observar que o número de escolas na zona rural era maior que na zona urbana e que o gerenciamento da maior parte das escolas da zona rural era de responsabilidade do município, enquanto as da zona urbana estavam sob a responsabilidade

12 Em divisão territorial datada de 1 de janeiro de 1979 ○ Município passou a ser constituído por seis distritos: Petrolina, Cristália, Curral Queimado, Dormentes, Lagoa Grande e Rajada. A Lei Estadual n. 10.625, de 1 de outubro de 1991, desmembrou de Petrolina os distritos de Lagoa e Dormentes para formar o novo Município de Dormentes. Maiores informações em História... (2018). 
do estado. Também se verifica que a quantidade de escolas de iniciativa privada na zona urbana tem número aproximado ao das de responsabilidade do Estado.

0 CERU Clementino Coelho foi construído na zona urbana, em uma região que na década de 1970 era considerada periférica, nomeada popularmente de "Buracão", segundo relatos de moradores locais, alunos e professores que frequentaram a instituição nesse período. Inicialmente foi ofertado apenas o ensino de $1^{\circ} \mathrm{grau}$.

No seu primeiro ano de funcionamento, em 1977, foram matriculados 1.137 alunos, da $1^{a}$ série à $5^{a}$ série, distribuídos nos turnos matutino, vespertino e intermediário, estendendo ao noturno somente no ano seguinte. A demanda por vagas aumentou progressivamente, chegando a 1.938 matrículas em 1981.

Ao todo somavam 12 turmas de primeira série, diferenciadas por ordem alfabética, cada turma composta de 30 a 35 alunos. Era a série que possuía maior número de turmas até o ano de 1980, seguida das turmas de $2^{a}$ série. Esse número diminuiu a partir de 1981, destacando-se um aumento progressivo nas turmas de $5^{a}$ e $6^{a}$ séries do $1^{\circ}$ grau. Além disso, foi possível localizar turmas da $5^{a}$ à $8^{a}$ série com até 54 alunos.

Esse número excedente de alunos somados aos quatro turnos de funcionamento era parte da estratégia da política educacional do período de ampliação de vagas, na tentativa de sanar a histórica negligência com o ensino elementar (SOUZA, 2008). Esse acesso massivo à escolarização significava um importante passo ao acesso à educação formal - em específico à população petrolinense.

Souza (2008), ao estudar a história da organização do trabalho escolar e do currículo no século XX, aponta que o acentuado aumento de matrículas nos anos 1960 e 1980 provocou mudanças no ensino.

\footnotetext{
A intensificação do processo de expansão de matrículas cada vez maior nos anos 60 e 70 levaram algumas escolas a funcionar em quatro turnos reduzindo drasticamente o tempo das atividades escolares, sem contar as classes com número excessivo de alunos. [...] inviabilizou horários para reuniões pedagógicas e discussões coletivas. (SOUZA, 2008, p. 266).
}

Criada inicialmente como a primeira escola com capaciadade para atender 1.200 no Municípo de Petrolina, o CERU Clementino Coelho logo perdeu o posto para outras escolas. A demanda de pais e alunos por mais vagas passou a exigir do poder público a ampliação em outras unidades, entre as quais a Escola de Petrolina (2.241), Escola Alfa Polivalente (1.797), 
Escola Marechal Antônio Alves Filho (1.397) e Escola Dom Malan (1.307). Essas escolas com elevados números de alunos estavam situadas na zona urbana da Cidade.

\section{PROGRAMA DE CONSTRUÇÃO E AMPLIAÇÃO DAS UNIDADES ESCOLARES}

0 CERU Clementino Coelho foi construído pelo Programa de Construção e Ampliação de Unidades Escolares, uma ação do Estado de Pernambuco. Esse Programa foi idealizado para cumprir com as exigências das instâncias governamentais, no que diz respeito à expansão da escolarização. 0 planejamento para a execução do Programa teve um caráter interdisciplinar, por reunir a atenção de administradores, arquitetos, professores, engenheiros e políticos, que se orientavam em dois pressupostos, o primeiro estava relacionado aos prédios escolares, isto é, não somente a sala de aula, mas toda a estrutura deveria ter a finalidade de propiciar experiências de aprendizagem, e no segundo, as experiências deveriam ser orientadas pelos fins educacionais da época.

Financiada pelo Polonordeste e pelo Fundo de Ação Social (FAS) da Caixa Econômica Federal, a implantação dos CERUs em Pernambuco custou aos cofres públicos $\mathrm{Cr} \$$ 100.000,00 (Cem Mil Cruzeiros). Os objetivos do Polonordeste foram colocados em prática pelo Programa de Desenvolvimento Rural Integrado (PDRI) e se integravam aos demais órgãos para o alinhamento de metas a serem cumpridas, ação esta que se destacava como inovadora (ALBURQUERQUE, 2011).

Os recursos do Programa destinaram-se à construção de 20 escolas tipo Centro de Educação Rural no Estado de Pernambuco. Os CERUs contemplados estavam localizados nas seguintes Mesorregiões: cinco no Sertão, oito no Agreste, seis na Zona da Mata e um na região Metropolitana. As regiões próximas à capital, Recife, receberam mais Centros que as demais. Os CERUs da microrregião Agreste Setentrional foram selecionados para sediar o projeto piloto, servindo de laboratório para a aplicação das estratégias educacionais do Sistema Integrado de Educação Rural (PERNAMBUC0, 1982).

13 Para maiores informações sobre a história da escola, ver Santos (2016). 
Mapa 1 - Mapa de Pernambuco destacando com círculos na cor preta os municípios contemplados com os CERUs

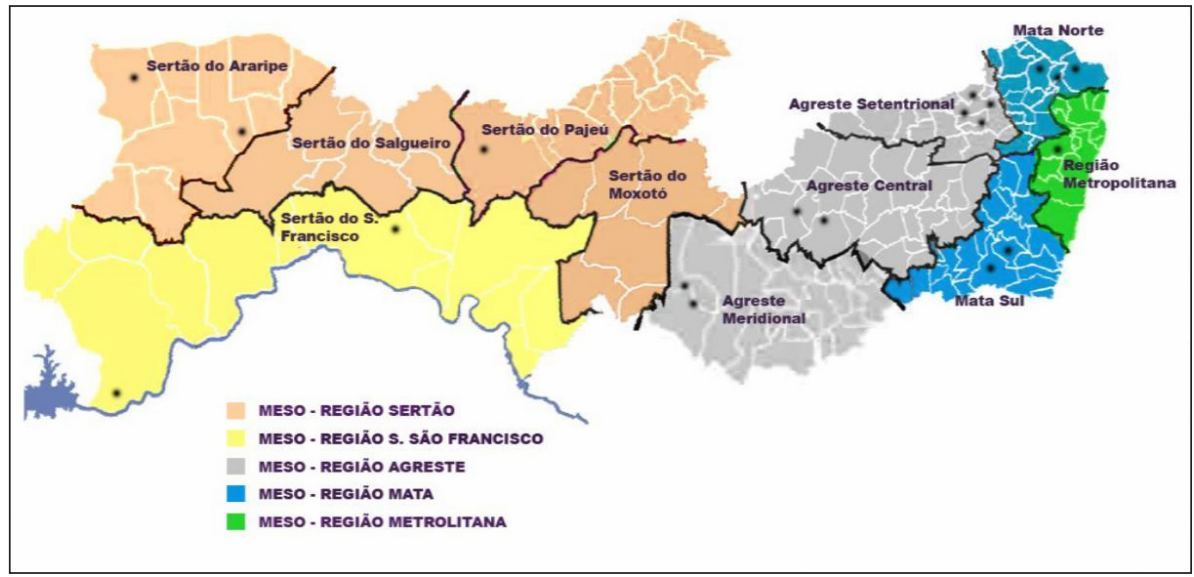

Fonte: adaptado de Mesorregiões... (2012).

Inicialmente foram construídas, progressivamente, 18 escolas até o ano 1978, segundo o relatório publicado no Periódico Educação de março de 1977 (PERNAMBUC0, 1977). Os CERUs de Pesqueira e Vicência foram os últimos a serem implantados.

Quadro 2 - Distribuição dos CERUs por mesorregiões e municípios

\begin{tabular}{|c|c|c|}
\hline Mesorregiões & Municípios & Centros de Educação Rural \\
\hline Metropolitana & São Lourenço da Mata & CERU Conselheiro Samuel Mac Dowell \\
\hline \multirow{6}{*}{ Zona da Mata } & Palmares & CERU Monsenhor Abílio Américo Galvão \\
\hline & Ribeirão & CERU João Lopes de Siqueira Santos \\
\hline & Barreiros & CERU Doutor Anthenor Guimarães \\
\hline & Condado & CERU Antônio Correia de Oliveira Andrade \\
\hline & També & CERU Frei Orlando \\
\hline & Vicência & CERU Doutor Joaquim Correia \\
\hline \multirow{7}{*}{$\begin{array}{l}\text { Agreste Central e Seten- } \\
\text { trional }\end{array}$} & São Vicente Férrer & CERU Coronel João Francisco \\
\hline & Limoeiro & CERU Profa. Jandira de Andrade Lima \\
\hline & Bezerros & CERU Eurico Queiroz \\
\hline & Gravatá & CERU Prof. Antônio Farias \\
\hline & São Caetano & CERU Prof. Agamenon Magalhães \\
\hline & Pesqueira & CERU José de Almeida Maciel \\
\hline & Bom Conselho & CERU José Ab́́lio \\
\hline Agreste Meridional & Garanhuns & CERU Francisco Madeiros \\
\hline Sertão do Pajeú & Serra Talhada & CERU Methódio de Godoy Lima \\
\hline
\end{tabular}




\begin{tabular}{|l|l|l|}
\hline \multirow{2}{*}{ Sertão do São Francisco } & Petrolina & CERU Clementino Coelho \\
\cline { 2 - 3 } & Belém do São Francisco & CERU Maria Emília Cantarelli \\
\hline \multirow{2}{*}{ Sertão de Araripina } & Araripina & CERU Luiz Gonzaga Duarte \\
\cline { 2 - 3 } & Bodocó & CERU João Carlos Lócio Almeida \\
\hline
\end{tabular}

Fonte: elaborado pelos autores, com base no Diário Oficial de Pernambuco de 1977 a 1984 e no Periódico Educação de 1977.

Quanto às orientações para a construção dos CERUs, o programa priorizava as cidades do interior com zonas de maior potencialidade agrícola, bem como adoção de estruturas que permitissem maior flexibilidade dos espaços internos, construção tipo modulado, divisórias removíveis, mão de obra local, exploração do uso de novos materiais de possível aquisição regional e de fácil manutenção e limpeza (PERNAMBUCO, 1982).

0 Relatório (ano 1975/1976) publicado no Periódico Educação de março de 1977 (PERNAMBUCO, 1977), ao tratar da implantação dos CERUs, aponta que a viabilidade das construções ocorreu pela flexibilidade do sistema modular de arquitetura escolar escolhido pela equipe de infraestrutura da Secretaria de Educação do Estado, adaptando as finalidades dos Centros de Educação Rural aos terrenos de topografias. Esse modelo mantinha algumas similitudes com os Ginásios Orientados para o Trabalho.14

A primeira característica se refere ao modelo arquitetônico, com salas estilo galpões equipadas para os componentes curriculares técnicos. Além dessas características, a capacidade para comportar 1.200 alunos e a estrutura curricular do ensino de $1^{\circ}$ Grau, delineadas pela política educacional da época, são semelhanças encontradas entre o CERU Clementino Coelho e o modelo dos Ginásios Orientados para o Trabalho, também conhecidos como Escolas Polivalentes. Nesse aspecto, como destaca Magalhães (2004), as instituições educativas mesmo apresentando diferenças com relação a sua natureza, finalidades e dimensões organizacionais, identificam-se em um mesmo processo de institucionalização.

No Estado de Pernambuco, as escolas de tipo CERU permaneceram em funcionamento por aproximadamente 30 anos. 0 CERU do Município de Limoeiro, por exemplo, onde foi desenvolvido integralmente o SIER, ainda mantém a mesma nomenclatura, bem como preserva a tradição dos Desfiles Cívicos, ato peculiar do período da Ditadura Militar.

Em 2005, essas escolas foram, gradativamente, aproveitadas para a instalação do projeto de Educação Integral, por meio das Escolas de Referência em Ensino Médio. 


\section{OS ESPAÇOS E A ARQUITETURA DO CERU CLEMENTINO COELHO}

De acordo com o Periódico Educação (PERNAMBUCO, 1976c), os CERUs foram planejados considerando os aspectos educacionais e o conceito de prédio escolar em consonância com a tendência pedagógica do período, baseada na racionalidade e produtividade, também conhecida no Brasil como tecnicismo. Sobre a relação entre a arquitetura escolar e a politica educacional vigente, Viñao Frago (2001) e Escolano (2001) destacam que o espaço escolar deve ser analisado como uma construção cultural que expressa e reflete, para além de sua materialidade, determinados discursos.

Com base na sua planta arquitetônica, o CERU Clementino Coelho possuía 14.622,65 $\mathrm{m}^{2}$ total de extensão e $2.433,96 \mathrm{~m}^{2}$ de área construída. A estrutura era composta de salas para componentes curriculares comuns, que eram localizadas nos corredores, e de salas estilo galpão para os componentes curriculares técnicos, que ficavam nos extremos dos corredores. Esses corredores eram extensos, sendo um na vertical, que interligava o setor administrativo da escola às salas de aula, e dois corredores na horizontal.

Viñao Frago (2001), ao tratar das relações entre a dimensão espacial e a dimensão educativa, adverte que a análise da estrutura escolar deve considerar a sua "localização ou adequação em relação aos outros espaços e lugares." (VIÑAO FRAGO, 2001, p. 75). No caso específico do Ceru Clementino Coelho, este ocupava a totalidade do quarteirão da rua, sendo a sua lateral esquerda, situada na extensa Avenida da Integração, que hoje interliga a zona sul, a central e o norte da Cidade. Com isso, percebe-se que há um planejamento da localização do edifício escolar, ao compreender que o seu ponto estratégico dava acesso a estudantes de diversas partes de Petrolina. Além disso, outro elemento que faz compreender o planejamento da escola é sua entrada principal, que não estava situada na avenida principal, mas na rua vertical que dava acesso à entrada ao bairro.

Esse vasto espaço, não sem razão, dialogava com as exigências curriculares da Lei n. 5.692/71, principalmente no que se refere ao núcleo diversificado, dai a necessidade de salas amplas para o desenvolvimento do ensino técnico e de espaços generosos para hortas e jardins, com destaque para as aulas de jardinagem e agricultura simples, além de diversos tipos de quadras para as aulas de educação fisica, pátios para a hora do recreio e refeitório para o momento da merenda.

Aspectos sobre os espaços da escola e sua arquitetura foram localizados no Anteprojeto do Programa de Construção e Ampliação de Unidades Escolares do Governo do Estado, de 1976. Esse documento, além de discriminar as escolas que seriam ampliadas ou 
construídas, aponta a quantidade de salas, mobílias, materiais de expediente e equipamentos para as salas dos componentes curriculares técnicos. No caso dos CERUs, deveria ser construída uma sala para cada componentes curricular técnico, oito salas de aula comum, secretaria, biblioteca, gabinete do diretor, banheiros masculino e feminino e cantina. No que se refere às técnicas de Práticas Agrícolas, o ambiente devia estar equipado com mesa para laboratório, extintor, armários, cadeiras sem braço, além de materiais para trabalhar com madeira, eletricidade e no campo.

A planta arquitetônica do CERU Clementino Coelho revela uma concepção e um estilo específico de espaço e arquitetura escolar. Isso é notório quando comparado aos pomposos modelos escolares do início do século XX $X^{15}$ ou com a precariedade das Escolas Isoladas e/ ou Reunidas ${ }^{16}$ na zona rural. Nesse sentido, a capacidade para receber um número maior de alunos impacta de forma diferente dos modelos escolares de outrora, refletindo, assim, nas relações interpessoais, nos modos como eram concebidas as práticas pedagógicas, na própria relação corpo e espaço.

Bastos Moura (informação verbal), ${ }^{17}$ que frequentou a escola na década de 1970, percebe esse impacto ao mencionar sua passagem da Escola Reunida km 2 para o CERU Clementino Coelho. Ele recorda que a forma como usava os espaços do CERU era diferente da Escola Reunida. Os momentos de recreação da nova escola eram sempre de muitas brincadeiras e movimentação corporal, por meio das corridas de pega-pega.

Erigido com base na racionalidade técnica - em termos de projeto - e alinhado com a economia vigente, o modelo arquitetônico do CERU Clementino Coelho privilegiava a luminosidade, a ventilação e a visibilidade, atributos voltados para o bem-estar do público que frequentava a lnstituição. Isso pode ser visto na planta arquitetônica a seguir.

15 Bencostta (2016, p. 9) explica que a construção de novos edifícios específicos para as escolas primárias públicas espalhadas do Brasil republicano "deveria funcionar como ponto de destaque na cena urbana, enquanto signo de ideal republicano de uma gramática discursiva arquitetônica que enaltecesse o novo regime."

16 No exame de Ávila (2013a), vários fatores contribuíram para o estado de "abandono" e a condição de inferioridade a que foi submetido o ensino rural nas primeiras décadas do regime republicano, entre os quais a posição de relevo a que foram alçadas as cidades no processo de modernização da sociedade brasileira.

17 As entrevistas constantes nesta seção foram submetidas e aprovadas pelo Comitê de Ética da Universidade de Pernambuco, Campus Petrolina, em 07/12/2017. Os entrevistados são identificados por pseudônimos. 
Figura 1 - Planta arquitetônica do CERU Clementino Coelho dimensionada em partes

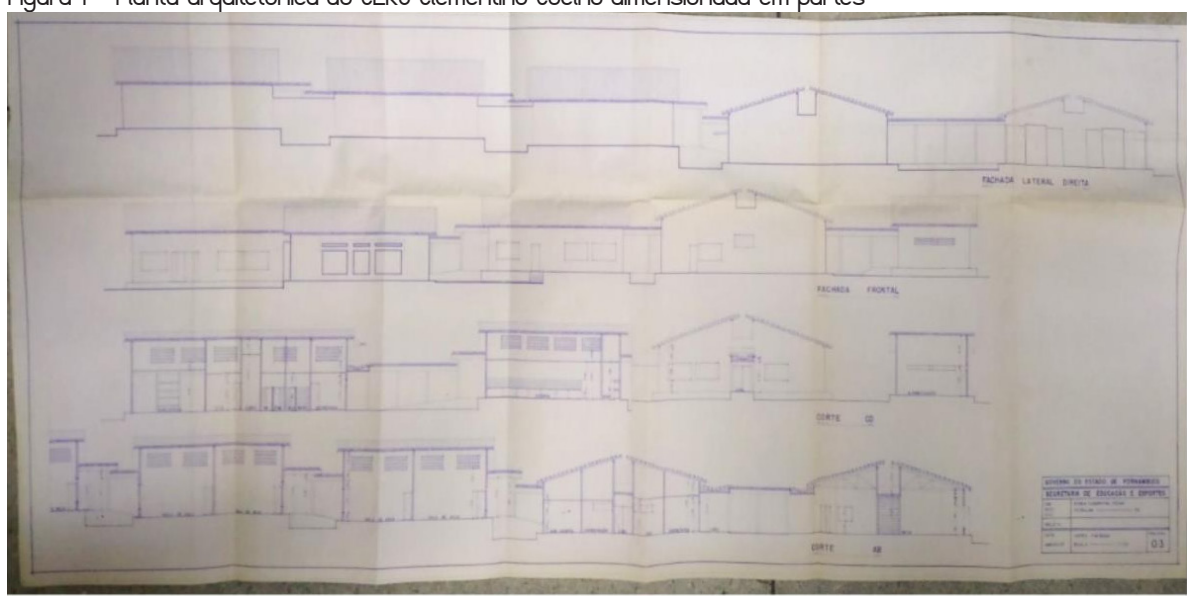

Fonte: acervo da Escola de Referência em Ensino Médio Clementino Coelho, Petrolina.

A arquitetura da escola pode ser considerada um dos atrativos para o elevado número de matrículas. 0 modelo arquitetônico, construído em um bairro simples periférico, chamava a atenção da população. Esse destaque não era sem propósito. Conforme o relatório sobre as construções dos CERUs, exposto no Periódico Educação (PERNAMBUCO, 1976c, p. 53), sobre a arquitetura do CERU Clementino Coelho: "Além dos requisitos técnicos e funcionais, uma atenção toda especial dedica-se à apresentação física, através de um tratamento plástico alegre e cuidadoso, atentando à influência do prédio da escola como elemento de estímulo e de liderança de comunidade."

Embora tenha-se instalado como uma unidade operativa do SIER, cuja finalidade era uma transformação ampla no conceito de Escola Rural e sua redefinição como foco irradiador e como incorporador de toda a população no processo educativo, até o momento não foi possível constatar a aplicação dos princípios e finalidades do CERU Clementino Coelho. Essa lacuna é decorrente da ausência de documentos da escola que comprovem a atuação do Sistema. No relatório anual do SIER de 1982 consta que havia a perspectiva de ampliação dos CERUs para o restante do Estado de Pernambuco.

\section{A ORGANIZAÇÃO CURRICULAR E AS TÉCNICAS AGRÍCOLAS}

Com a promulgação da Lei n. 5.692/71 a educação passou a vigorar o ensino de $1^{\circ}$ Grau, com duração de oito anos e caráter obrigatório, destinado aos alunos de 7 a 14 anos, e o ensino de $2^{\circ}$ Grau, com duração de 3 ou 4 anos, destinado à formação profissional 
dos adolescentes (BRASIL, 1971). Para ajustar a nova regulamentação ao sistema de ensino, o currículo foi organizado em um Núcleo Comum e em uma Parte Diversificada. A partir dessa regulamentação, o CERU Clementino Coelho compôs seu currículo da seguinte forma:

Quadro 3 - Componentes curriculadres ministrados no CERU Clementino Coelho (1977 a 1984)

\begin{tabular}{|c|c|c|c|c|}
\hline \multicolumn{5}{|c|}{ Parte Comum } \\
\hline Comunicação e expressão Integração social & \multicolumn{4}{|c|}{$1^{a}, 2^{a}, 3^{a}$ e $4^{a}$ séries } \\
\hline \multicolumn{5}{|c|}{ Parte Diversificada } \\
\hline & $5^{a}$ & $6^{a}$ & $7^{a}$ & $8^{\circ}$ \\
\hline Língua Portuguesa & $x$ & $x$ & $x$ & $x$ \\
\hline Educação Artística & $x$ & $x$ & $x$ & $x$ \\
\hline Matemática & $x$ & $x$ & $x$ & $x$ \\
\hline História & $x$ & $x$ & $x$ & $x$ \\
\hline Geografia & $x$ & $x$ & $x$ & $x$ \\
\hline Religião & $x$ & $x$ & $x$ & $x$ \\
\hline Ciências e Práticas de Saúde & $x$ & $x$ & $x$ & $x$ \\
\hline Educação Fisica & $x$ & $x$ & $x$ & $x$ \\
\hline Inglês & $x$ & $x$ & $x$ & $x$ \\
\hline Educação Moral e Cívica & - & - & $x$ & - \\
\hline OSPB & - & - & - & $x$ \\
\hline \multicolumn{5}{|c|}{ Formação específica } \\
\hline Práticas Integradas do Lar & $x$ & $x$ & $x$ & $x$ \\
\hline Práticas Comerciais & $x$ & $x$ & $x$ & $x$ \\
\hline Práticas Agrícolas & $x$ & $x$ & $x$ & $x$ \\
\hline
\end{tabular}

Fonte: elaborado pelos autores a partir dos dados disponíveis nos arquivos do CERU Clementino Coelho.

Esses componentes curriculares foram esquadrinhados nas atas de resultados finais e nas fichas individuais dos alunos. Os componentes que compunham o Núcleo Comum, de acordo com o Parecer n. 853/71, eram determinados pelo Conselho Federal de Educação. De acordo com Souza (2008, p. 271), o Núcleo Comum “circunscrevia o mínimo necessário para o indivíduo adaptar- se às exigências da sociedade urbano-industrial e tecnológica."

Cabia aos Conselhos Estaduais de Educação organizar os componentes curriculares constitutivos da parte diversificada, sobretudo às de formação especial, e distribuí-los aos estabelecimentos de ensino com base na economia e cultura local (SOUZA, 2008). No caso do CERU, a formação Especial se deu pela Resolução n. 3/73 do Conselho Estadual de Educação de Pernambuco. Com isso, essa formação especial era ministrada nos 
últimos quatro anos do $1^{\circ}$ Grau, com vistas ao despertar vocacional, funcionando aos moldes dos “Ginásios Orientados para o Trabalho".

No livro A escola de $1^{\circ}$ Grau e o currículo de formação especial, de 1980, elaborado pela Secretaria de ensino de $1^{\circ}$ e $2^{\circ}$ Graus, destinado aos professores, estão descritas orientações do que seria esse modo de formação. Por esse documento, a formação especial seria realizada nas séries finais do ensino de $1^{\circ}$ Grau, mas em menor extensão que a educação geral, com o objetivo de sondar aptidões e iniciar para o trabalho. E como iniciação para o trabalho, a formação especial estava diretamente vinculada às necessidades reais e atuais do mercado de trabalho local ou regional (BRASIL, 1980, p. 9).

Sobre componentes vocacionais, Marta Medeiros, aluna que frequentou o CERU Clementido Coelho nesse período, recorda que "[...] tinha uma aula de técnicas agrícolas, eu adorava, lembro que a gente ia para uma hortazinha, até hoje me lembro do professor." (informação verbal). Segundo ela, as "aulas eram de lazer" ou, como refere Bastos Moura (informação verbal), outro aluno que frequentou a escola, os componentes curriculares de Práticas eram considerados "mais leves" em relação aos demais.

Cunha (2005, p. 176), ao analisar a educação profissional no contexto da implantação do ensino vocacional por meio da Lei n. 5.692/71, lembra que

não se sabia bem o que seria essa iniciação profissional, nesse momento do percurso educacional dos alunos, embora a crença dos formuladores da nova política educacional fosse a de que ela permitiria aos alunos pobres trabalharem, tão logo deixassem a escola.

No que se refere à organização, os componentes curriculares de caráter vocacional eram optativos, segundo relatos dos entrevitados e constatação nas fichas individuais dos alunos. De acordo com a professora Dora Souza (informação verbal), "os meninos geralmente escolhiam Práticas Agrícolas ou as Comerciais, enquanto que as meninas escolhiam Práticas Integradas do Lar." Para Bastos Moura (informação verbal), havia certa resistência dos meninos em cursar este componente. Porém, ao examinar as fichas dos alunos, foi visto que ele também era escolhido pelos meninos.

As aulas eram ministradas duas vezes por semana. Tinha os dias de aulas teóricas e tinha os dias de aulas práticas. 0 professor dava orientação, tinha texto, mandava fazer pesquisa, tinha prova também. Só quando a gente tinha um bom conhecimento de tudo que ele passava era que a gente ia para horta. [...] Ele ensinava o cuidado com a terra, a adubação, não queimar a terra, proteger algumas plantinhas que ajudavam no cultivo daquela outra maior. Necessariamente nem todas as vezes nós cuidávamos da terra, havia o rodizio entre alunos. Nas do lar, a pessoa aprendia a pintar, 
costurar, cozinhar, mas eu lembro bem fixado que Técnicas Agrícolas foi a que eu escolhi, e eu amava essa disciplina. (Medeiros) (informação verbal).

Esse processo de experimentação e de manipulação de objetos era uma forma de desenvolver as aptidões técnicas para que os alunos, ao iniciarem o ensino de $2^{\circ} \mathrm{Grau}$, estivessem cientes da escolha do curso profissionalizante. Com isso, ainda que o objetivo desse nível de ensino estivesse voltado para uma sondagem vocacional e iniciação ao trabalho, é perceptível uma finalidade pedagógica a partir do uso das aulas práticas e/ou das oficinas. Segundo Cunha (2005), a finalidade pedagógica dessas aulas remete às propostas da Escola Nova.

Zuza Martins, filha de comerciantes, hoje artesã e empresária, lembra de sua resistência para não cursar o componente Técnicas Comerciais, pois já dominava os conhecimentos básicos, como preencher duplicata, cheques, recibos, técnicas de vendas, entre outros. A aluna lembra que gostava das aulas de Práticas Integradas do Lar, porque nela eram oferecidas outras atividades além dos cuidados domésticos (informação verbal).

\footnotetext{
[...] Minha mãe gostava de costurar e minha vó de bordar, fazer esses serviços assim, e eu sempre estava no meio querendo aprender, mas fui aprender mesmo na escola. [...] lá não só aprendia a fazer as comidinhas, mas tinha muita aula de arte, pintura, quadros. Um dia desse estava lembrando com minha mãe que eu sempre gostei de mexer com arte, com a técnica do craquelê, que eu aprendi na disciplina com a professora Joselaide, eu peguei até um jarro de mainha para fazer nele. Mainha disse: "fala com professora Joselaide e agradece a ela." (Zuza Martins) (informação verbal).
}

Embora o fato de a mãe e a avó de Zuza Martins lidarem com atividades manuais tenha despertado o lado artístico da aluna, a passagem pelo componente curricular Práticas Integradas do Lar teve influência na escolha da profissão que segue atualmente.

Mais informações sobre o funcionamento desses componentes curriculares foram possiveis de serem encontradas nos arquivos pessoais da professora Dora Souza, produzidos no período em que atuou como supervisora escolar, em 1983.

Com diversos formatos e múltiplas funcionalidades, os cadernos escolares como fontes historiográficas são, segundo Mignot (2008, p. 7), "quase invisíveis":

\footnotetext{
Passamos por eles despreocupadamente, sem enxergar que falam dos alunos, dos professores, dos pais, dos projetos pedagógicos, das práticas avaliativas, dos valores disseminados, em palavras e imagens, bem como das prescrições e interdições que conformam sua produção, sua circulação e seus usos.
} 
0 caderno da supervisora, produto material de uma cultura escolar vivenciada no CERU Clementino Coelho, contém entre os diversos registros, informações referentes aos componentes curriculares do currículo de formação especial. No caderno, em suas primeiras folhas (Figura 2) foram encontradas informações sobre uma reunião realizada com os professores de Práticas Agrícolas, Práticas Comerciais e Práticas Integradas do Lar. A reunião, datada no dia 10 de março de 1983, tinha como objetivo a elaboração de um projeto intitulado de Empresa Didática e contava com todos os professores responsáveis pelos componentes curriculares práticos.

Figura 2 - Caderno da supervisão escolar com dados sobre os componentes curriculares de formação especial (1981)

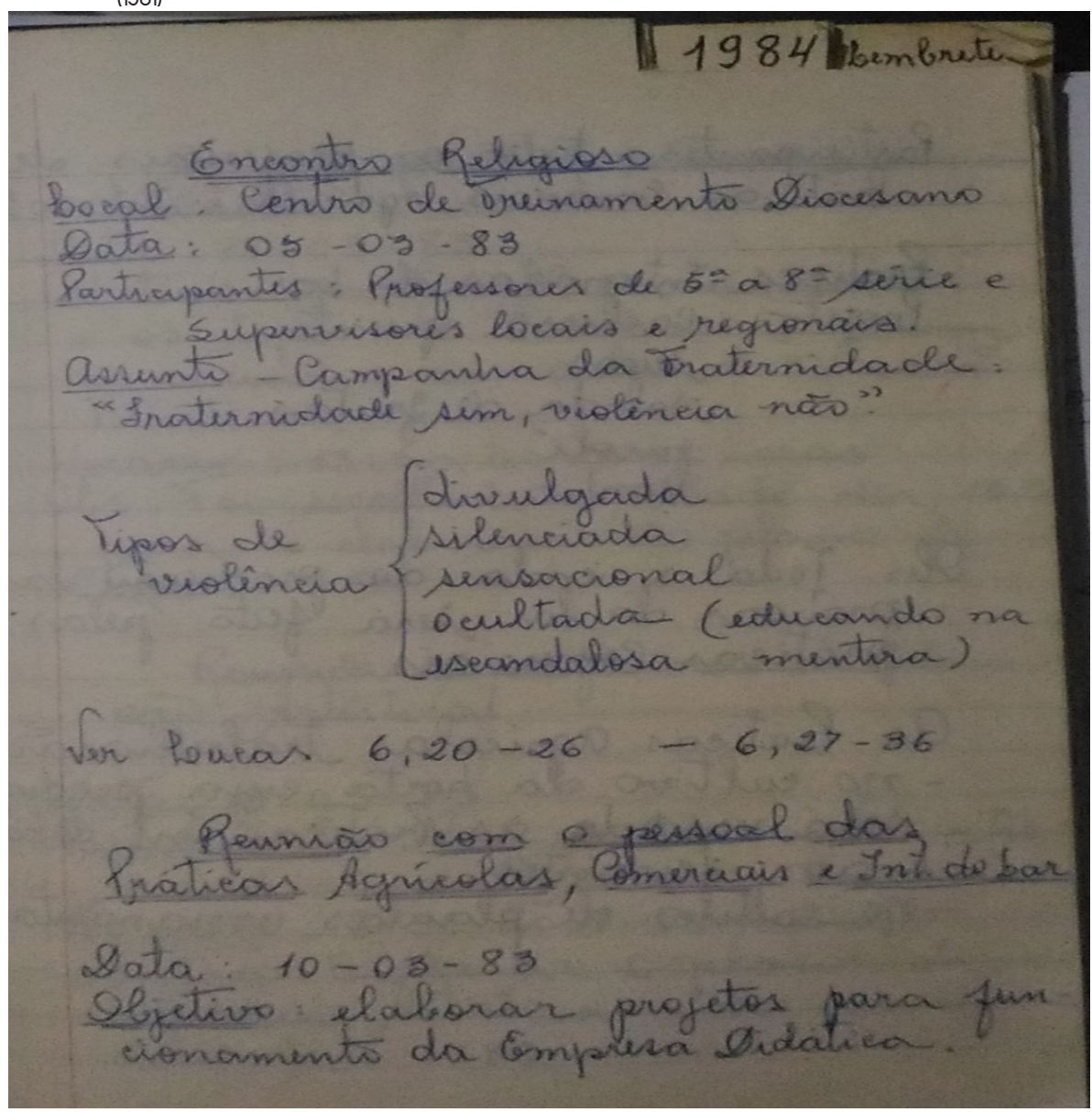

Fonte: arquivos pessoais da ex-professora Dora. 
A Empresa Didática funcionava de maneira integrada, ou seja, todos os componentes curriculares buscavam interrelacionar seus conteúdos com sequências de atividades que deveriam ser desenvolvidas em conjunto. Nesse sentido, em Prática Integrada do Lar os alunos ficavam encarregados de preparar comidas e bebidas, como cachorroquente, sucos, salada de fruta, picolé e sonho. Essas comidas deveriam ser vendidas em Práticas Comerciais. Já o cultivo da horta era realizado em Práticas Agrícolas, e sua produção era destinada aos feirantes e à cozinha da escola.

Nesse ciclo de produção, ao tentar reproduzir uma empresa, os alunos não só adquiriam conhecimentos acerca dos componentes curriculares práticos, como também mobilizavam outros saberes, como os de Matemática, Língua Portuguesa, Ciências e Artes. Além disso, era um momento privilegiado para a cooperação e o divertimento dos alunos, como relataram na entrevista os alunos Bastos Moura e Zuza Martins.

\section{CONSIDERAÇÕES FINAIS}

Neste trabalho, buscamos analisar a origem do Centro de Educação Rural Clementino Coelho, no Município de Petrolina, no período entre os anos 1977 e 1984, como parte do Sistema Integrado de Educação Rural. Para a análise, a pesquisa de cunho histórico e documental seguiu a abordagem da Nova História Cultural, de modo geral, da Cultura Escolar, tomando como fontes de pesquisa a planta arquitetônica, fichas de matrícula, livro de cadastro das unidades escolares de Pernambuco, periódicos da Secretaria da Educação, atas de resultados finais e relatórios, além de entrevistas com ex-estudantes e ex-professores.

A articulação teórico-metodológica possibilitou detectar que a origem do CERU Clementino Coelho remonta a um grande programa, que foi o Sistema Integrado de Educação Rural, idealizado pelo Instituto Interamericano de Cooperação Agrícola, organismo internacional especializado em cooperação técnica para o desenvolvimento da agricultura. Esse Sistema, em Pernambuco, implantou 20 centros de educação rural. Um dos critérios utilizados para a sua implantação na Cidade de Petrolina está diretamente relacionado ao potencial da agricultura irrigada. A vinculação da Instituição com o SIER ocorreu pela instalação consoante as características geográficas e econômicas regionais, porém até o momento não foi possível constatar a efetivação dos princípios e finalidades do SIER no CERU Clementino Coelho em Petrolina. Essa lacuna é decorrente da ausência de documentos da escola que atestem sobre a atuação do Sistema na região. No relatório anual do SIER de 1982 consta que havia a perspectiva de ampliação dos CERUs para o restante do Estado de Pernambuco. 
Outro aspecto identificado refere-se ao modo de funcionamento e ao espaço físico. A ampla arquitetura do CERU estava coadunada com a política educacional do período, no que diz respeito ao processo de expansão escolar, por meio da obrigatoriedade de escolarização, bem como era uma estrutura articulada com a tendência pedagógica do período, baseada na racionalidade e produtividade, ou seja, na tendência tecnicista.

Observou-se, ainda, que o CERU funcionou inicialmente como uma escola de primeiro grau; seu currículo seguia as regulamentações da Lei n. 5.692/71, principalmente no que se refere ao ensino vocacional com os componentes curriculares técnicos, destinado às turmas de $5^{a}$ a $8^{a}$ séries. Como a escolha dos componentes curriculares técnicos concernia ao Conselho Estadual de Educação, pela característica do CERU, foram-lhe destinadas as Práticas Agrícolas, Práticas Comerciais e Práticas Integradas do Lar. As Práticas Agrícolas, em especial, foi um componente marcante para os alunos, pois o fato de o CERU desenvolvê-las por meio de projeto integrado, como a Empresa Didática, conferia dinamicidade às aulas. Além disso, a horta e o fazer artístico das aulas de Práticas Integradas do Lar estavam presentes de forma afetiva nas memórias dos alunos entrevistados que passaram pela Instituição.

Durante a realização da pesquisa surgiram alguns desafios, entre os quais, a identificação de pesquisas que tratam sobre os programas e projetos implementados no Estado de Pernambuco entre as décadas de 1970 e 1980, bem como sobre a história dos Centros de Educação Rural criados nesse período. Somam-se a esses a necessidade de estudos e avaliações sistematizadas sobre tais programas, especialmente sobre a atuação do IICA e do SIER nas diferentes regiões do País.

Para finalizar, este estudo aponta para a necessidade de investigações mais aprofundadas acerca do papel desempenhado pelo Sistema Integrado de Educação Rural no Estado de Pernambuco na criação dos Centros de Educação Rural.

\section{REFERÊNCIAS}

ALBUQUERQUE, A. B. Polonordeste: as politicas de desenvolvimento econômico e social para o semiárido durante o regime militar (1964/1985). 2011. १२4f. Dissertação (Mestrado em História) - Universidade Federal de Pernambuco, Recife, 2011.

ALBERTI, V. Manual de história oral. 3. ed. Rio de Janeiro: Editora FGV, 2005.

ÁVILA, V. P. S. História do ensino primário rural em São Paulo e Santa Catarina (1921-1952): uma abordagem comparada. São Paulo: Cultura Acadêmica, 2013a. Disponível em: http://www.culturaacademica. com.br/_img/arquivos/9788579834875.pdf. Acesso em: 12 maio 2018.

ÁVILA, V. P. S. A escola no tempo: a construção do tempo em escolas isoladas (Florianópolis - 19301940). Florianópolis: Ed. Udesc, 2013b. 
BENCOSTTA, M. L. Cândido de Abreu: projetos do primeiro urbanista da cidade de Curitiba do início do século XX. Revista Brasileira de História, São Paulo, v. 36, n. 73, p. 231-254, dez. 2016. Disponível em: http://dx.doi.org/10.1590/1806-93472016v36n73_012. Acesso em: 22 abr. 2018.

BRASIL. Decreto-lei n. 74.794, de 30 de outubro de 1974. Dispõe sobre a criação do Programa de Desenvolvimento de Áreas Integradas do Nordeste (Polonordeste). Brasilia, DF, 31 out. 1974. Disponível em: http://www2.camara.leg.br/legin/fed/decret/1970-1979/decreto-74794-30-outubro-1974-423254-publicacaooriginal-1-pe.html. Acesso em: 22 abr. 2018.

BRASIL. Lei $n .5 .692$, de 11 de agosto de 1971. Estabelece as diretrizes e bases da educação nacional. Diário Oficial da União, Brasília, DF, 11 ago. 1971. Disponível em: http://www2.camara.leg.br/legin/fed/ lei/1970-1979/lei-5692-11-agosto-1971-357752-publicacaooriginal-1-pl.html. Acesso em: 21 abr. 2018.

BRASIL. Ministério da Educação e Cultura. Secretaria de Ensino de $1^{\circ}$ e $2^{\circ}$ Graus. A escola de $1^{\circ}$ grau e o currículo (1 parte). 2. ed. Brasilia, DF, 1980.

BRASIL. Relatório anual (1982). Escritório IICA/Brasil. Brasília, DF: [s.n.], 1983.

CALAZANS, M. J. C. et al. Políticas educacionais: questões e contradições da Educação Rural no Brasil. In: WERTEIN, J.; BORDENAVE, J. D. (org.). Educação rural no terceiro mundo: experiências e novas alternativas. Rio de janeiro: Paz e Terra, 1981. p. 161-197.

CUNHA, L. A. 0 ensino profissional da irradiação do industrialismo. 2. ed. São Paulo: Ed. Unesp; Brasília, DF: FLACSO, 2005.

ESCOLANO, A. Arquitetura como programa. Espaço-escola e currículo. In: FRAGO VIÑAO, A.; ESCOLANO, A. (org.). Currículo, espaço e subjetividade: a arquitetura como programa. Tradução Alfredo Veiga-Neto. 2. ed. Rio de Janeiro: DP\&A, 2001.

FRATTINI, R. M. A implantação da Reforma do Ensino de $1^{\circ}$ e $2^{\circ}$ Graus no Estado de São Paulo nas Páginas da Imprensa (1971-1982). 2011. 205 f. Dissertação (Mestrado em Educação) - Faculdade de Ciências e Letras, Universidade Estadual Paulista, São Paulo, 2011.

HISTÓRIA Municipal. Governo do Estado de Pernambuco. BDE: Base de Dados do Estado. Disponível em: http://www.bde.pe.gov.br/visualizacao/Visualizacao_formato2.aspx?.codFormatacao=745\&Codlnforma cao=915\&Cod=1. Acesso em: 22 abr. 2018.

INSTITUTO INTERAMERICANO DE COOPERAÇÃO PARA AGRICULTURA. Modernização da Agricultura e Cooperação Internacional. 25 anos do IICA no Brasil. [S.l.]: [s.n.], 1990.

JARDIM, P. P. Do ensino das técnicas à educação geral: vestígios da cultura escolar de um ginásio orientado para o trabalho (Juazeiro do Norte/CE - 1977 a 1987). 2017. 85 f. Dissertação (Mestrado em Educação) - Universidade de Pernambuco, Petrolina, 2017. 
LE GOFF, J. História e memória. 5. ed. Campinas: Ed. Unicamp, 2003.

LE GOFF, J. História e memória. Tradução Irene Ferreira, Bernardo Leitão, Suzana Ferreira Borges. 7. ed. Campinas, SP: Ed. Unicamp, 2013.

MAGALHÃES, J. Tecendo Nexos: história das instituições educativas. Bragança Paulista: Editora Universitária São Francisco, 2004.

MESORREGIÕES do Estado de Pernambuco. Pernambuco: lugares e olhares, 2012. Disponivel em: http:// pernambucolugareseolhares.blogspot.com/2012/08/mesor regioes-do-estado-de-pernambuco.html. Acesso em: 18 mar. 2018.

MIGNOT, A. C. V. Um objeto quase invisível. In: MIGNOT, A. C. V. (org.). Cadernos à vista: escola, memória e cultura escrita. Rio de Janeiro: Ed. UERJ, 2008.

NORA, P. Entre memória e história - a problemática dos lugares. Tradução Yara Aun Khoury. Revista Projeto História, São Paulo, n. 10, p. 7-28, dez. 1993. Disponível em: https://revistas.pucsp.br/index. php/revph/article/view/12101/87 63. Acesso em: 26 out. 2017.

PADILHA, A. de S. Petrolina no tempo, no espaço, na vez. Centro de Estudos de História Municipal Fiam. Recife: [s.n.], 1982.

PERNAMBUCO. Secretaria de Educação. Diretoria de Desenvolvimento e Normas. Departamento de Planejamento. Sistema Integrado de Educação Rural - SIER. Recife: [s.n.], 1982.

PERNAMBUCO. Secretaria de Educação. Diário Oficial do Estado de Pernambuco, Recife, ano 53, n. 198, 1976a.

PERNAMBUCO. Secretaria de Educação. Jornal do Commercio, Recife, n. 246, 1976b.

PERNAMBUCO. Secretaria de Educação. Periódico Educação, Recife, 1976c.

PERNAMBUCO. Secretaria de Educação. Relatório 1975-1976. Periódico Educação, Recife: Cepe, 1977.

PESAVENTO, S. J. História \& história cultural. Belo Horizonte: Autêntica, 2003.

REPRESENTAÇÃO Brasil. Instituto Interamericano de Cooperação para Agricultura. Disponivel em: http:// www.iicabr.iica.org.br/. Acesso em: 22 abr. 2018.

SANTOS, K. L. Do Ginásio Industrial de Petrolina à Escola Marechal Antônio Alves Filho: vestígios da cultura escolar (1960-1970). 2016. Trabalho de Conclusão de Curso (Graduação em História) - Universidade de Pernambuco, Petrolina, 2016.

SOUZA, R. F. História da organização do trabalho escolar e do currículo no Século XX: (ensino primário e secundário no Brasil). São Paulo: Cortez, 2008. 
TÁVORA FLLHO, A. F.; LEITE, P. S. A estratégia do desenvolvimento rural integrado. Resvista de Administração Pública, Rio de Janeiro, v. 12, n. 3, p. 159-182, jul./set. 1978. Disponível em: http://bibliotecadigital. fgv.br/ojs/index.php/rap/article/viewFile/7471/5940. Acesso em: 29 jun. 2018.

VIÑO FRAGO, A. Do espaço escolar e da escola como lugar: propostas e questões. In: FRAGO, A.V.; ESCOLANO, A. (org.). Currículo, espaço e subjetividade: a arquitetura como programa. Rio de Janeiro: DP\&A, 2001.

WERTEIN, J. Sistema Integrado de Educação Rural - SIER: a experiência de Pernambuco. In: WERTEIN, J.; BORDENAVE, J. D. (org.). Educação rural no terceiro mundo: experiências e novas alternativas. Rio de janeiro: Paz e Terra, 1981. p. 327-347.

Endereços para correspondência: Rua do Morango, n. 44, 56312-800, Bairro Rio Corrente, Petrolina, Pernambuco, Brasil; manu-garciah@hotmail.com 